\title{
Sockeye: A 1-D Heat Pipe Modeling Tool
}

Joshua Hansel

David Andrs

Ray Berry

Richard Martineau

September 2019

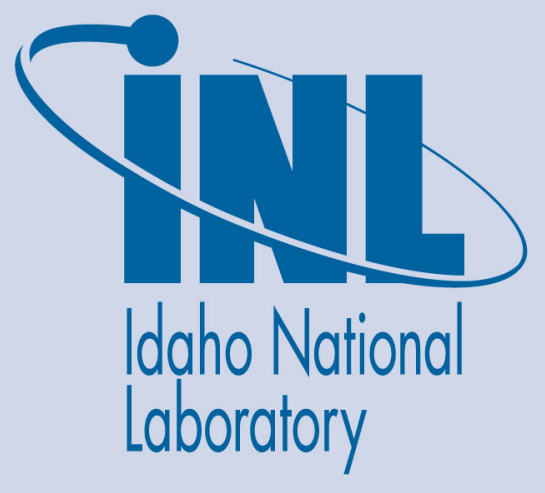

The INL is a U.S. Department of Energy National Laboratory operated by Battelle Energy Alliance 


\section{DISCLAIMER}

This information was prepared as an account of work sponsored by an agency of the U.S. Government. Neither the U.S. Government nor any agency thereof, nor any of their employees, makes any warranty, expressed or implied, or assumes any legal liability or responsibility for the accuracy, completeness, or usefulness, of any information, apparatus, product, or process disclosed, or represents that its use would not infringe privately owned rights. References herein to any specific commercial product, process, or service by trade name, trade mark, manufacturer, or otherwise, does not necessarily constitute or imply its endorsement, recommendation, or favoring by the U.S. Government or any agency thereof. The views and opinions of authors expressed herein do not necessarily state or reflect those of the U.S. Government or any agency thereof. 


\title{
Sockeye: A 1-D Heat Pipe Modeling Tool
}

\author{
Joshua Hansel \\ David Andrs \\ Ray Berry \\ Richard Martineau
}

September 2019

\section{Idaho National Laboratory Modeling and Simulation Department Idaho Falls, Idaho 83415}

http://www.inl.gov

\author{
Prepared for the \\ U.S. Department of Energy \\ Office of Nuclear Energy \\ Under DOE Idaho Operations Office \\ Contract DE-AC07-05ID14517
}




\section{ABSTRACT}

Sockeye is a 1-D MOOSE-based application for modeling heat pipes. Sockeye is aimed at modeling heat pipes with annular wick and contains two-phase fluid property packages for sodium and potassium working fluids. Sockeye adapts the two-phase flow model from RELAP-7 to the simulation of heat pipes, by accounting for the capillary pressure in pressure relaxation terms. Additionally, a simple, aggregate heat transfer model exists for transitioning from temperatures below the melting temperature of the working fluid. Results are presented for an example test problem, and some future work is discussed. 


\section{Introduction}

Sockeye is a 1-D heat pipe modeling tool based on the MOOSE framework[1] currently under development. Sockeye leverages the two-phase flow model from RELAP-7 [2]. Additionally, a model is included to simulate heat transfer to the solid phase before the working fluid has melted. Figure 1 shows the assumed heat pipe configuration: an annular wick separates a liquid annulus from the vapor core. Currently, Sockeye provides equations of state packages for sodium and potassium, but it could be easily extended to other fluids. Finally, Sockeye incorporates a 2-D finite element heat structure to simulate transient heat conduction in the solid wall, as well as thermomechanics.

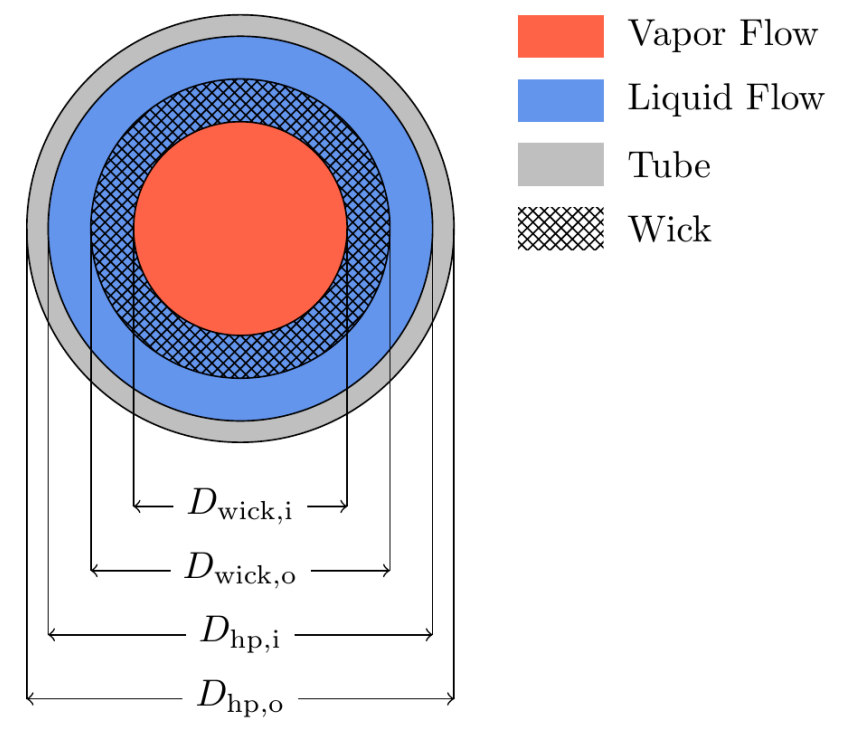

Figure 1: Cross section of a heat pipe modeled with Sockeye

This report is organized as follows: Section 2 describes the models used by Sockeye, including the flow equations and the aggregate melting model, Section 3 shows some results obtained with Sockeye, and Section 4 gives some conclusions and describes some planned future work. 


\section{Models}

This section provides a summary of the models used in Sockeye. For a complete description on these models, please refer to the Sockeye theory manual[3].

\subsection{Two-Phase Flow Model}

The equations of two-phase flow are based on the two-phase flow equations used in RELAP-7 [2] but are adapted to reflect an annular heat pipe configuration. The PDEs for phase $k$ include balance equations for volume fraction, mass, momentum, and energy:

$$
\begin{gathered}
\frac{\partial \alpha_{k} A}{\partial t}=\mu\left(p_{k}+\Delta p_{k \rightarrow j}^{\mathrm{cap}}-p_{j}\right) A-\frac{\Gamma_{k \rightarrow j}^{\mathrm{int}} a_{\mathrm{int}} A}{\rho_{\mathrm{int}}} \\
\frac{\partial \alpha_{k} \rho_{k} A}{\partial t}+\frac{\partial \alpha_{k} \rho_{k} u_{k} A}{\partial x}=-\Gamma_{k \rightarrow j}^{\mathrm{int}} a_{\mathrm{int}} A \\
\frac{\partial \alpha_{k} \rho_{k} u_{k} A}{\partial t}+\frac{\partial \alpha_{k}\left(\rho_{k} u_{k}^{2}+p_{k}\right) A}{\partial x}=p_{\text {int }} \frac{\partial \alpha_{k}}{\partial x} A-F_{k}^{\mathrm{wall}} A+\alpha_{k} \rho_{k} g_{x} A \\
\frac{\partial \alpha_{k} \rho_{k} E_{k} A}{\partial t}+\frac{\partial \alpha_{k} u_{k}\left(\rho_{k} E_{k}+p_{k}\right) A}{\partial x}=-\bar{p}_{\text {int }} \mu\left(p_{k}+\Delta p_{k \rightarrow j}^{\mathrm{cap}}-p_{j}\right) A-F_{k}^{\text {wall }} u_{k} A+\alpha_{k} \rho_{k} g_{x} u_{k} A \\
+q_{\mathrm{wall} \rightarrow k} P_{\mathrm{wall}}+q_{\mathrm{int} \rightarrow k} a_{\mathrm{int}} A-\Gamma_{k \rightarrow j}^{\mathrm{int}} E_{k}^{\mathrm{int}} a_{\mathrm{int}} A .
\end{gathered}
$$

Note that the volume fraction equation is needed only for one of the phases; the other is eliminated with the constitutive relation $\alpha_{\ell}+\alpha_{v}=1$, bringing the total number of PDEs to seven.

The volume fraction equation source terms correspond to pressure relaxation and phase change. The mass (continuity) equation source term corresponds to phase change. The momentum equation source terms correspond to interfacial pressure forces due to volume fraction gradients, wall friction, and gravity. The energy equation source terms correspond to pressure relaxation, wall friction, gravity, wall heat transfer, interfacial heat transfer, and phase change.

These equations are discretized using a finite volume method, described in detail in the RELAP7 theory manual[2].

\subsection{Aggregate Melting Model}

When the temperature of the heat pipe working fluid is below its melting point, the working fluid is in the solid state, and thus the two-phase flow equations described previously do not apply. The melt transient inside a heat pipe is very complex; to simulate it from first principles would require multi-dimensional three-phase flow capability, which is beyond the scope of Sockeye. Instead, Sockeye provides a simple heat balance capability to perform aggregate heat transfer to the entire working fluid. When the temperature of the entire mass reaches the operating temperature, the two-phase flow simulation is activated.

During the melting phase, the following initial value problem is solved:

$$
m \frac{\mathrm{d} h}{\mathrm{~d} t}=\int_{\partial \Omega} q \mathrm{~d} A, \quad h(0)=h\left(p_{0}, T_{0}\right),
$$


where $m$ is the mass of the working fluid, $h$ is the specific enthalpy of the mass, $\partial \Omega$ is the boundary of the mass, $q$ is the heat flux to the mass at a given spatial location, and $h(p, T)$ is the specific enthalpy of the mass (whatever phase it is in), as a function of pressure and temperature. The heat flux can be modeled as

$$
q=\mathrm{h}\left(T_{\text {wall }}-T\right),
$$

where the heat transfer coefficient $\mathrm{h}$ can be supplied by a closure relation or a user-supplied function along the length. When $T(h) \geq T_{\mathrm{op}}$, the melting phase ends, and the two-phase flow phase begins. 


\section{Results}

This section shows an example of some Sockeye results. In this test problem, a heat pipe is subjected to a linear power ramp to $1000 \mathrm{~W}$ and run until a steady state is detected. The end-of-ramp heat flux profile is shown in Figure 2.

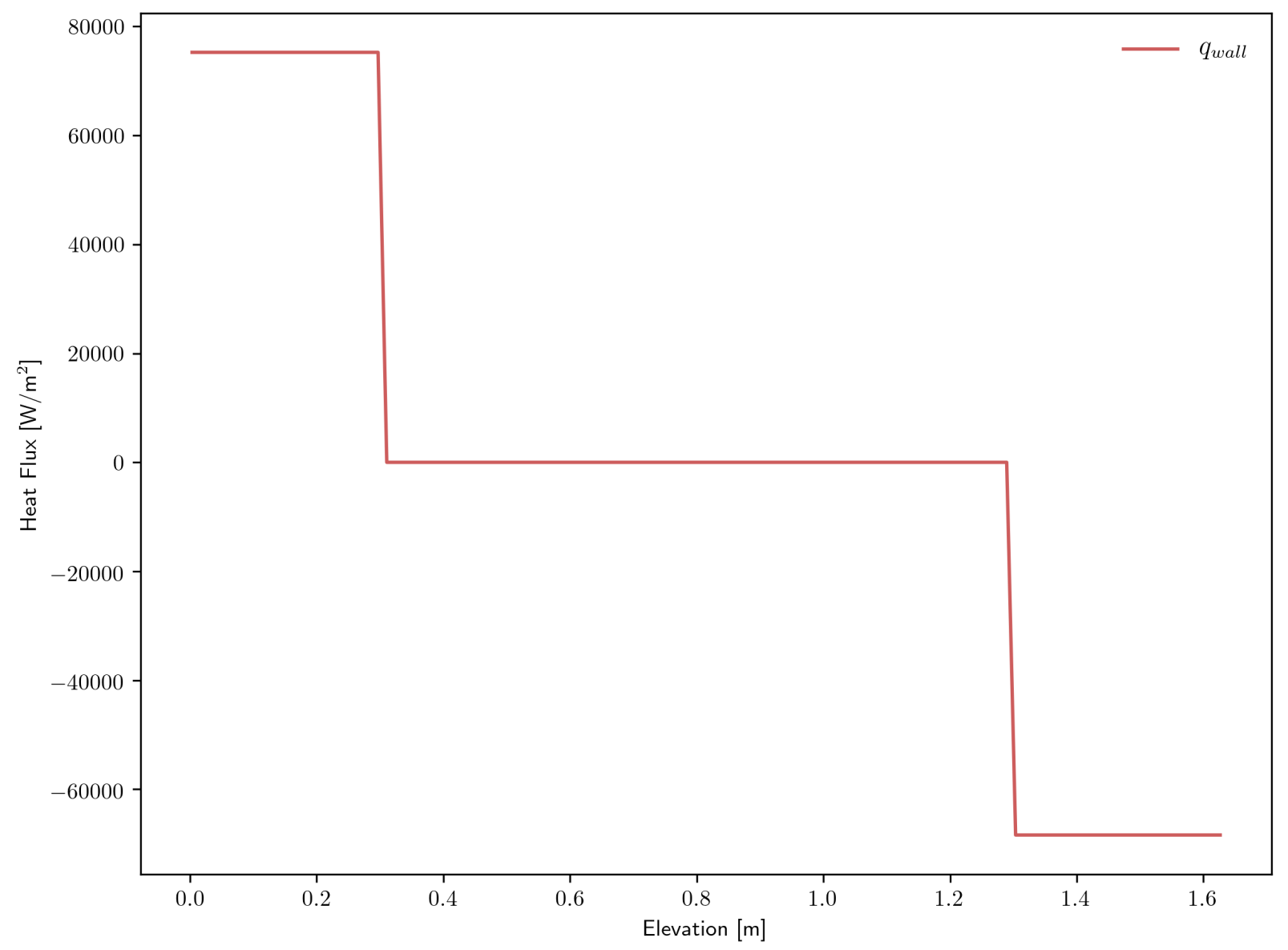

Figure 2: Heat flux profile for example problem

Figure 3 shows the steady-state void fraction profile. Also shown on the figure are the base void fraction (corresponding to a flat interface at the inner surface of the wick) and the upper and lower bounds of the model, corresponding to the interface being fully hemispherical, inwards or outwards, from the inner work surface. The void fraction's relation to the flat void fraction determines the capillary pressure that appears in the pressure relaxation terms.

Figure 4 shows the steady-state pressure profiles. The equilibrium pressures are governed by the capillary pressure difference computed using the void fraction. One can see that the pressures cross at the point where $\alpha_{v}$ crosses $\alpha_{v, 0}$ in Figure 3 .

Figure 5 shows the steady-state velocity profiles. The liquid velocity may appear to be zero but is actually just a negative number with a small magnitude, due to the large differences in density between the phases. The vapor velocity has the expected shape; it increases in the evaporator region, is relatively constant in the adiabatic region, and then decreases in the condenser region. 


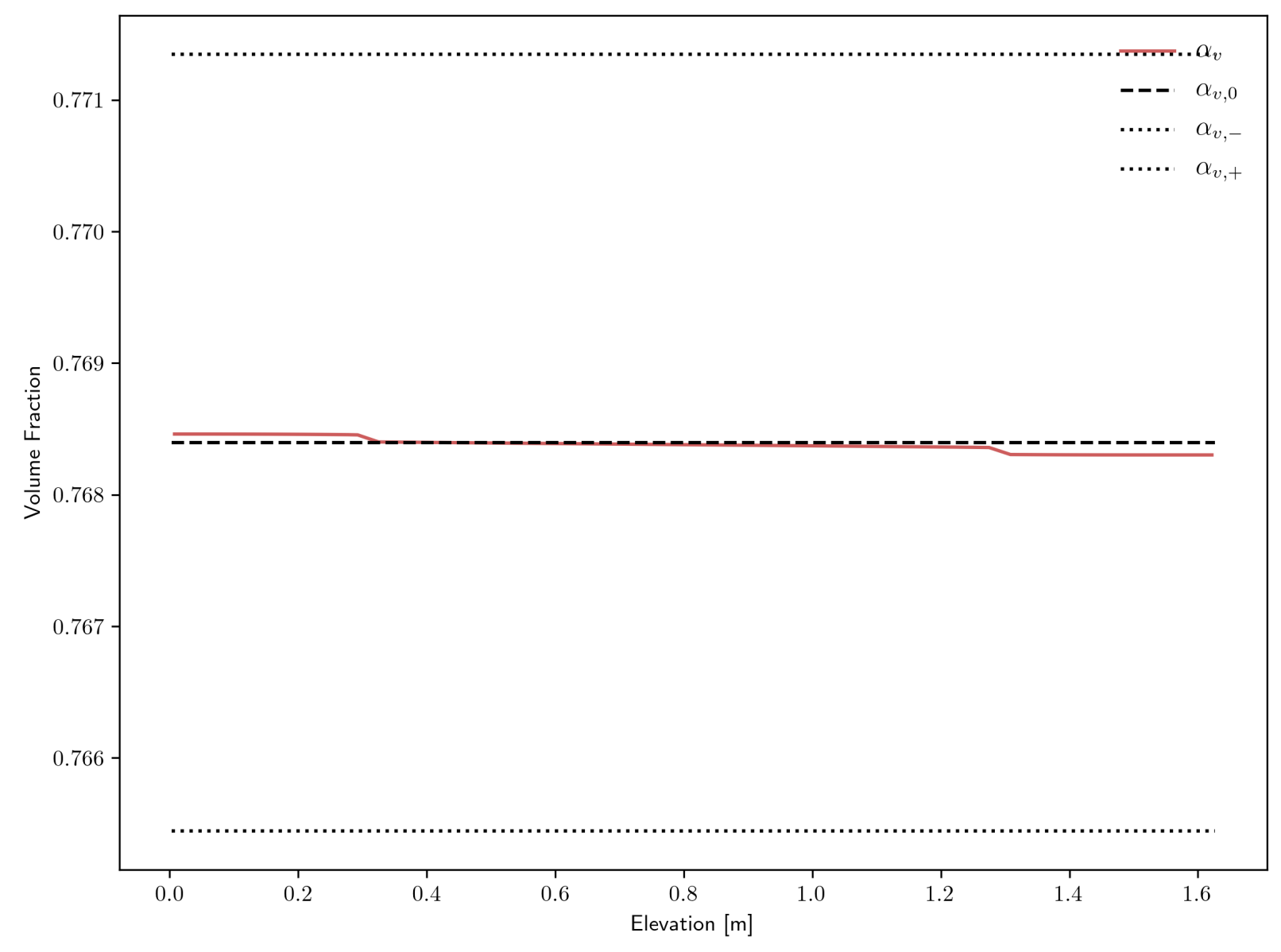

Figure 3: Computed volume fraction profile for example problem

Figure 6 shows the steady-state temperature profiles. Here, the nearly-isothermal operation typical of heat pipes can be observed.

Figure 7 shows the temperature profile in the 2-D heat structure for this problem. Note that the radius of the heat pipe is strethed by a factor of 100 for visualization purposes. The inner wall of the heat pipe tube is on the bottom; the outer wall is on the top. 


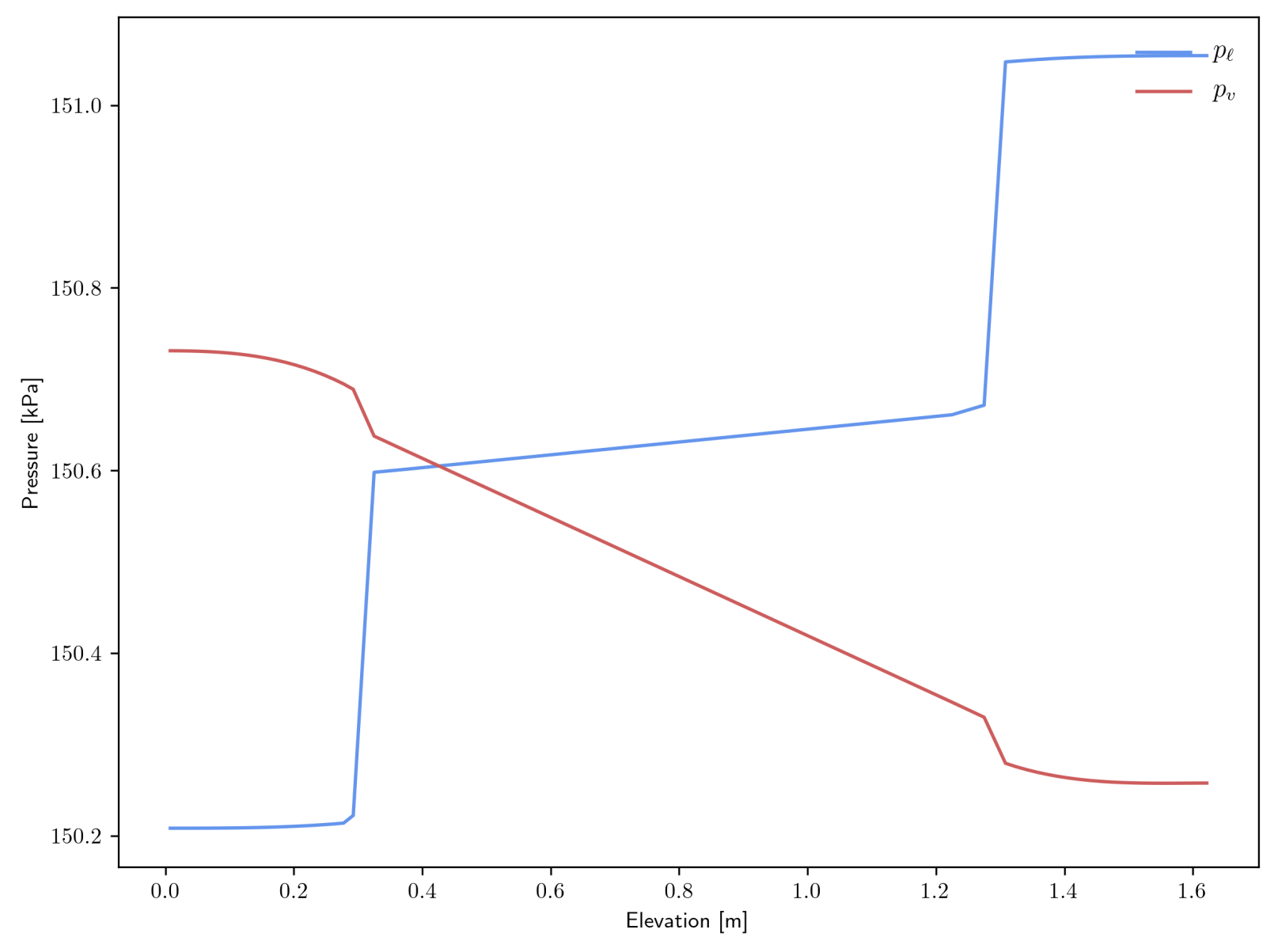

Figure 4: Computed pressure profiles for example problem 


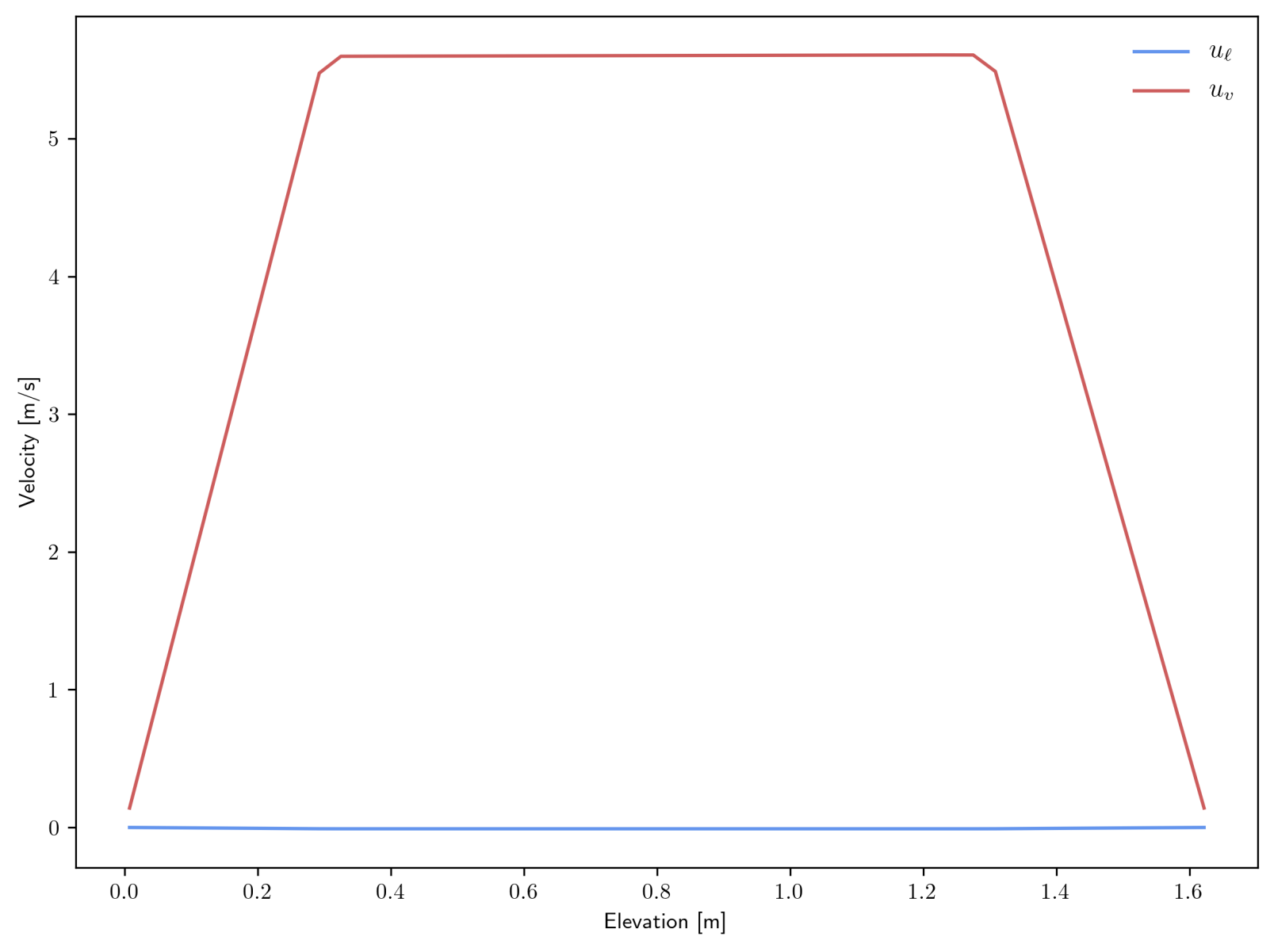

Figure 5: Computed velocity profiles for example problem 


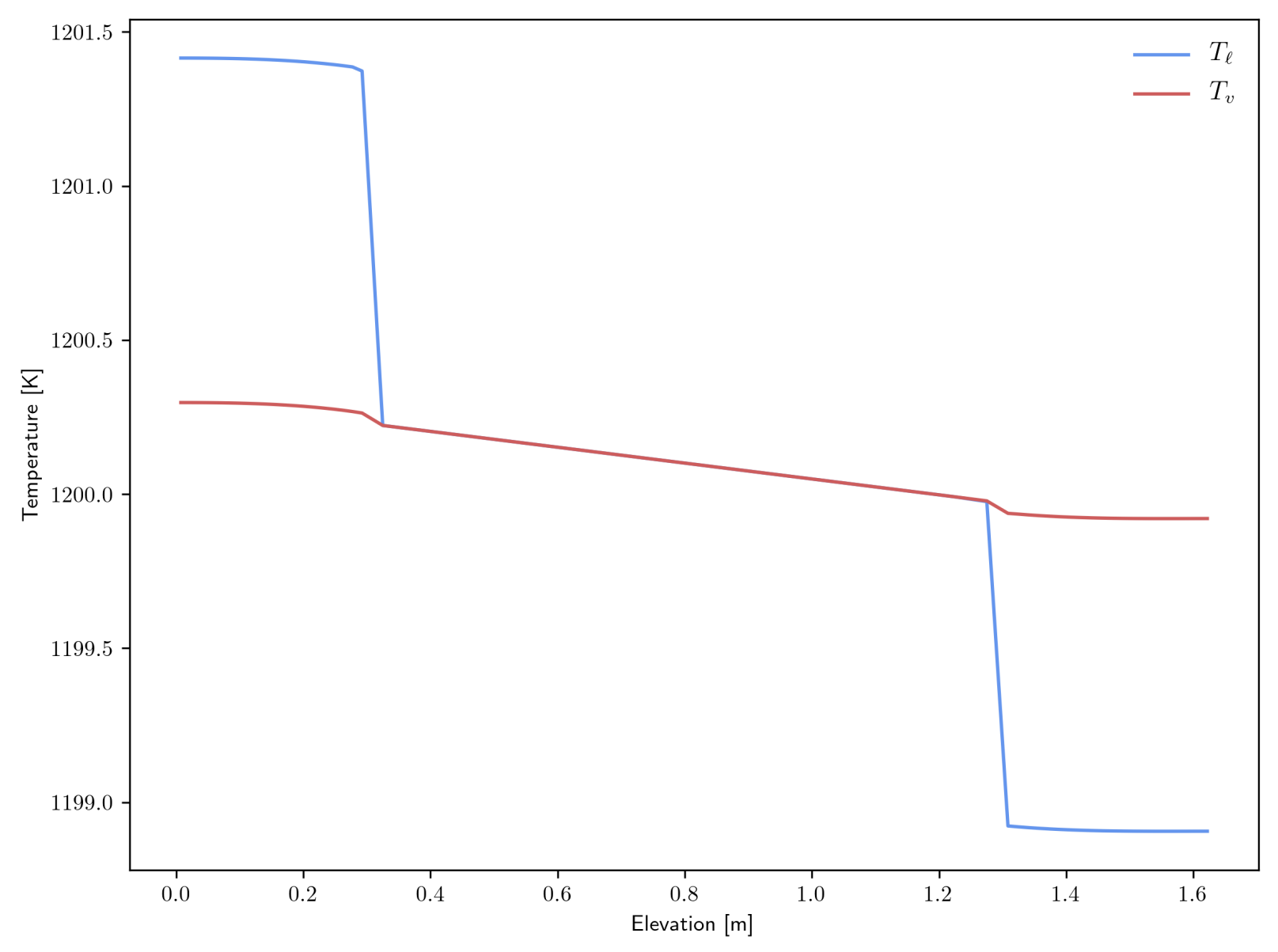

Figure 6: Computed temperature profiles for example problem

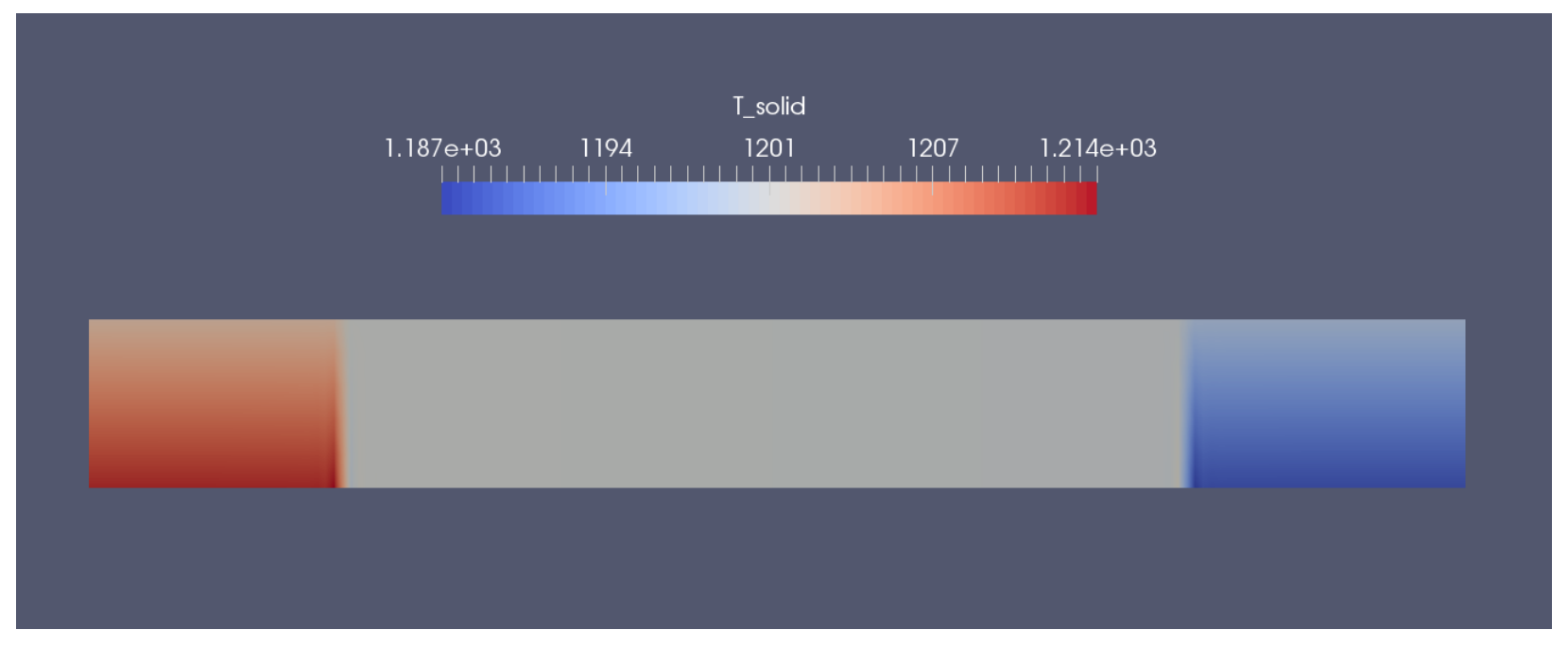

Figure 7: Temperature profile in 2-D heat structure 


\section{Conclusions}

The current Sockeye model is able to demonstrate some basic heat pipe physics but is still undergoing model improvement. Sockeye results still need to be compared with experimental data. A number of experiments have been proposed to provide data for Sockeye validation, and some experimental data is already existent and obtainable.

A number of model improvements are planned, such as the development/refinement of closure relations, including capillary pressure, friction/pressure loss, heat transfer coefficients, and mass transfer rates. Additionally, plans exist to attempt to predict some of the operational limits of the heat pipe, such as the boiling limit, capillary limit, etc. Other plans include the development of practical means of switching between solid and fluid models. 


\section{References}

[1] Derek R. Gaston, Cody J. Permann, John W. Peterson, Andrew E. Slaughter, David Andrš, Yaqi Wang, Michael P. Short, Danielle M. Perez, Michael R. Tonks, Javier Ortensi, Ling Zou, and Richard C. Martineau. Physics-based multiscale coupling for full core nuclear reactor simulation. Annals of Nuclear Energy, 84:45-54, 2015.

[2] R. A. Berry, J. W. Peterson, H. Zhang, R. C. Martineau, H. Zhao, L. Zou, D. Andrš, and J. E. Hansel. RELAP-7 theory manual. Technical Report INL/EXT-14-31366, Idaho National Laboratory, March 2018. Revision 3.

[3] J. E. Hansel, R. A. Berry, D. Andrš, and R. C. Martineau. Sockeye theory manual. Technical Report INL/EXT-19-54395, Idaho National Laboratory, June 2019. 